\title{
CREATININE AND CREATINE KINASE RATIO IN BLOOD OF DIFFERENT BODY TYPES - A NEW APPROACH.
}

\author{
Anupam Bandyopadhyay and Pritha Chatterjee \\ Department of Physiology. Post-Graduate Section, Serampore College. Serampore. West Bengal. India
}

\begin{abstract}
Purpose: The inconsistencies and variations of creatine kinase level due to modifiable and nonmodifiable factors were the basis of this study. The aim was to find out the relationships between creatinine and creatine kinase in the blood of somatotypes.
\end{abstract}

Methods: The 122 males, aged 10 to 20 years, were classified according to their somatotypes. Somatotypes were measured by the ISAK method. By standard laboratory methods, creatinine and creatine kinase estimate. The IBM SPSS version 24 is used for calculation. One way ANOVA followed by post hoc tests was performed to compare the variables among the three groups $(p<0.05)$.

Results: Creatinine level in the blood insignificantly deferred among the three somatotypes. The significant differences $(p<0.05)$ were found in creatine kinase level in the blood and creatinine/creatine kinase ratio among the three dominant Somatotypes. Creatine Kinase was significantly higher in Ectomorphs (212 U/L) than Endomorphs. Ectomorphs and mesomorphs have crossed normal creatine kinase levels (35 -175 U/L). The creatinine/creatine kinase ratio was found highest in endomorphs and lowest in the ectomorphs and significantly differed in three Somatotypes.

Conclusion: Creatinine production remains the same, indicating production of Creatinine is independent of specific body types. A significant higher Creatine Kinase level in Ectomorphs over Endomorphs showed fat content was not associated with it. Significant differences in Creatinine / Creatine Kinase ratio among Somatotypes suggested its relevance between cellular and morphological relationships and might uses as biomarkers.

Keywords: Creatinine, Creatine Kinase, Creatinine/Creatine Kinase Ratio, Somatotypes 


\section{THEORETICAL BACKGROUND}

The serum creatinine and creatine kinase (CK) have pro diagnostic importance for renal dysfunction and tissue damage, respectively. Both are maximally synthesis within the skeletal myocytes and a few in cardiomyocytes and the brain. It reports that the serum's usual sources of creatine kinase are primarily due to muscular dystrophy during activities. In myocardial infarction and stroke, creatine kinase release increases in the serum. In cerebral diseases, brain tissues release creatine kinase. In high-intensity physical work, mitochondrial creatine kinase converts creatine into creatine phosphate. In the cytosol, creatine phosphate is converted into creatinine and inorganic phosphate by spontaneous degradation and enters the bloodstream. Creatine Phosphate with the help of ADP, resynthesizing ATP for the instant energy supply during vigorous muscular contractions. The creatine kinase acts as a core enzyme of the energy-producing circuit in myocytes. The rate of creatinine production from creatine phosphate in the myocytes is directly proportional to creatine kinase's activity, and its production rate increases during physical exercise. The primary source of creatinine in the serum is creatine phosphate in the myocytes. The creatine kinase is released from the cell to the blood during cellular disturbances (Totsuka et al.,2002). The eccentric type muscle contractions lead to degrees of mechanical damage in the myocytes and cause creatine kinase release by dysfunctioning the ATPase pumps. An increase in proteolytic enzyme activities can augment the permeability of the myocytes, and thus creatine kinase leakages take place, though the exact mechanism is not precise (Khan, 2009). Increased serum creatine kinase level in muscle damage is broadly varied. In different pathological conditions like myocardial infarction, Rhabdomyolysis and strenuous physical activities, serum creatine kinase increased much to fold, but how it cleared from the blood has not been known (Huerta et al.,2005). It mentioned that the creatine kinase value found in the serum depends on the secretions of creatine kinase, degrees of enzyme activity of released creatine kinase and its clearance from the serum (Thompson et al., 2006). According to the findings of Perrone R D et al. (1992), creatinine produces from creatine non-enzymatically (Perrone et al., 1992). Taylor has found $1-2 \%$ of muscle creatine is converted to creatinine each day (Taylor, 1989). The reference range of creatinine is 61.9 - 114.9 micromol/l (Landry-Bazari, 2020). Creatinine level in the blood depends on its production in the cell, mainly from creatine phosphate non-enzymatically and indirectly by providing more creatine in the myocytes (Figure 1). The creatinine production rate is modulated by regulating the formation of creatine phosphate, and creatine kinase is the concerned enzyme. Creatine kinase activity is regulated by AMP-activated protein kinase, which depends upon the proportion of creatine and creatine phosphate in the myocytes. But phosphocreatine, especially in the muscle, is associated with the instant supply of energy and resynthesis of ATP (Ponticos et al., 1998). So, the primary sources of creatinine in the blood are the breakdown of phosphocreatine for producing or resynthesizing ATP to continue the phosphagen system in working muscles.

Creatinine and creatine kinase ratio might be an elementary reflector and coordinator between the cell and extracellular fluid-related with different body types. This crosssectional study is based on the fact that although it has immense variations in ranges, it is still an essential indicator of muscle dystrophy. Besides, variations in normal ranges 
might be minimized and appropriate if they express with Somatotypes. But, extensive research needs for establishing this new concept.

The distribution and amount of muscles in an individual are genetically predetermined. Physical activities can change the muscle mass and fat content of the body. The somatotyping technique can assess these changes. Changes that occur due to physical activities should involve the cellular metabolic activities of an individual. Muscle mass and fat content are not maintained without influencing the body's metabolic demands. Due to body types and activities differences, different variables' physiological and biochemical reference values defer in trained and sedentary persons. Almost all International reference values available are mainly categorised according to age, gender, ethnicity etc. but not based on body types Marianne et al., 2012). This study has emphasised some controversial and important blood variables directly associated with muscular activities in active individuals.

\section{METHODS}

One hundred twenty-two male trained players aged between 10-20 years participated in this cross-sectional study. Individual National Standard of Living Index and Sports Competition Anxiety Tests carries out on each participant. Blood samples were taken in the departmental laboratory, Serampore College, on three consecutive days. Consent took from each participant, their parents, and the club authorities. Permission took from the Institutional Human Ethics Committee.

\section{SOMATOTYPING}

All players were measured on the consecutive three days by the Level 1 Anthropometrists accredited by the International Society for Advancement of Kinanthropometry (ISAK) according to the methods stated in the ISAK manual (Lower, 2011). after completion of their physical training.

Stature measured by a stadiometer (minimum measurement range $60 \mathrm{~cm}$ to 220 $\mathrm{cm}$ ).Body mass estimated with an electronic weighing machine (SECA). Skinfold thickness (biceps, triceps, subscapular, supraspinal) was measured to determine the fat $\%$ and total fat content with a Slim Guide skinfold calliper (CESCORF). It required a constant closing compression of $10 \mathrm{~g}$./ sq.mm throughout the range of measurements. The subject had to assume a relaxed standing position with the right arm hanging by the side. Biceps skinfold was measured from the point on the arm's anterior surface at the level of mid-acromiale-radiale landmark amid the muscle belly. For triceps skinfold measurement, from the issue on the posterior surface of the arm, in the midline, at the level of marked mid-acromiale -radiale landmark. The fold runs obliquely downwards from the subscapular juncture at 45 degrees angles to measure the subscapular skinfold. From the intersecting point of two lines, supraspinale skinfold measurement was taken. The line from the marked iliospinale to the anterior axillary border. The horizontal line at the level of marked iliocristale. Anthropometric tape, non-extensible, flexible, no wider than $7 \mathrm{~mm}$ and having a stub of at least $4 \mathrm{~cm}$ before zero lines (CESCORF) used for measuring girth (arm and calf) and circumferences ( chest, waist, hip, mid-thigh, upper thigh). Arm-girth measures from the arm circumference at the 
mid-acromiale-radiale site, perpendicular to the long axis of the arm. In the same way, calf girth measures from the leg circumference at the medial calf skinfold site level, perpendicular to its long axis. The circumference of the thorax measured at the level of the mesosternale site, perpendicular to the long axis of the thorax, was the chest circumference. On the other hand, waist circumference is the circumference of the abdomen at the narrowest point between the lower costal border and the top of the iliac crest, perpendicular to the long axis of the trunk. The circumference measures from the buttocks at the level of their greatest posterior protuberance, perpendicular to the long axis of the trunk. Mid-thigh circumference measures at the level of the midtrochanterion-tibiale lateral site, perpendicular to the long axis. In contrast, upper thigh circumference measured from the thigh $1 \mathrm{~cm}$ distal to the gluteal fold site, perpendicular to its long axis. Sliding callipers (CESCORF) have a branch length of at least $10 \mathrm{~cm}$, an application face width of $1.5 \mathrm{~cm}$, and be accurate within $0.05 \mathrm{~cm}$ were used for measuring breadth (epicondylar humerus and femur). Biepicondylar humerus and femur measure from a distance between the most lateral aspect of the lateral humeral and femoral epicondyle and the most medial humeral and femoral epicondyle, respectively.

\section{ANTHROPOMETRIC VARIABLES}

All the measurements were done with the same instrument for three consecutive days in all individuals. The players were constantly motivated with verbal encouragement to cooperate fully with measure.

- Biceps Skinfold thickness (mm)

- Triceps Skinfold Thickness (mm)

- Subscapular Skinfold Thickness (mm)

- Supraspinale Skinfold Thickness (mm)

- Medial calf skinfold Thickness(mm)

- Upper arm circumference (cm)

- Medial calf circumference (cm)

- Bi-epicondylar humerus circumference $(\mathrm{cm})$

- Bi-epicondylar femur circumference $(\mathrm{cm})$

For somatotype rating, the Heath Carter method (Heath-Carter, 1967) followed. The following equations use-

Endomorph $=-0.7182+0.1451 \times \Sigma S F-0.00068 \times \Sigma S F 2+0.0000014 \times \Sigma S F 3$ where $\Sigma S F$ $=$ (sum of triceps,subscapular and supraspinale skinfolds) multiplied by $(170.18 /$ height in $\mathrm{cm}$ ).

Mesomorph $=0.858 \times$ humerus breadth $+0.601 \times$ femur breadth $+0.188 \times$ corrected arm girth $+0.161 \times$ corrected calf girth - height $\times 0.131+4.5$.

With the help of height-weight ratio (HWR), three different equations were used to calculate ectomorph:

If $\mathrm{HWR}$ is greater than or equal to 40.75 then, 
Ectomorph $=0.732 \times \mathrm{HWR}-28.58$.

If HWR is less than 40.75 and greater than 38.25

then, Ectomorph $=0.463 \times \mathrm{HWR}-17.63$.

If HWR is equal to or less than 38.25were calculated, Ectomorph $=0.1$.

\section{BLOOD VARIABLES}

The skilled technician took four ml of blood from the antecubital vein from the 122 trained male athletes in three consecutive days-blood collected in heparinised vials before their regular physical exercise. Quantitative estimation of two variables, creatine kinase and creatinine, was estimated using kits manufactured by Avecon Healthcare Private Limited, Transasia Biomedicals Limited. Creatinine/ Creatine kinase Ratio calculated by simple mathematical calculations.

CREATINE KINASE - MODIFIED IFCC METHOD (Chatterjee et al., 2017).

Creatine kinase has three isoenzymes CK-MM, CK-BB and CK-MB. A CK test measures the total level but does not distinguish between the three isozymes. CK reversibly catalyses the transfer of a phosphate group from creatine phosphate to adenosine diphosphate (ADP) to form creatine and adenosine triphosphate (ATP) products. The ATP formed is used to produce glucose-6- phosphate and ADP from glucose. This reaction is catalysed by hexokinase, which requires magnesium ions for maximum activity. The glucose 6-phosphate oxidises by the enzyme glucose-6-phosphate dehydrogenase, simultaneously reducing the coenzyme nicotinamide adenine dinucleotide to give reduced nicotinamide adenine dinucleotide hydrogen and 6phosphogluconate. The rate of absorbance increase at $340 / 660 \mathrm{~nm}$ due to the formation of reduced nicotinamide adenine dinucleotide phosphate is directly proportional to the activity of CK in the sample.

Substrate Start Assay: In a dry test tube labelled as T, $0.8 \mathrm{ml}$ enzyme reagent and $0.02 \mathrm{ml}$ sample were added. It incubates at $37^{\circ} \mathrm{C}$ for $1 \mathrm{~min}$, and $0.2 \mathrm{ml}$ of starter reagent is added. It mixed well, and the initial absorbance was noticed at $340 \mathrm{~nm}$, and the absorbance reads after every 1, 2 and 3 min.

Sample Start Assay: In a dry test tube labelled as T, $1 \mathrm{ml}$ of working reagent was added. It incubates at $37^{\circ} \mathrm{C}$ for $1 \mathrm{~min}$ and adds $0.02 \mathrm{ml}$ of starter reagent. It mixes well, and the initial absorbance is noticed at $340 \mathrm{~nm}$, and the absorbance reads after every 1, 2 and 3 min. The mean absorbance change per minute is calculated.

SERUM CREATININE-KINETIC METHOD (Sabbagh, 1988).

The kinetic method involves no deproteinisation. It is a rapid method and needs a low sample volume. The absorbance measures at $510 \mathrm{~nm}$. Wavelength with the help of a Spectrophotometer. The Creatinine/Creatine Kinase Ratio was obtained by dividing the estimated value of creatinine by creatine kinase.

\section{STATISTICAL ANALYSIS}

IBM SPSS version 24 was used for calculation. According to somatotype and age calculated, each mentioned variable's mean values and standard deviation were calculated among three groups. One way ANOVA performs for comparing each of the 
variables among the three groups. The probability of error due to random sampling is rejected at the level of $p<0.05$. A significant difference exists among the groups in ANOVA, so post hoc analysis performs through Scheffe's test to find out exactly which groups are different from each other.

\section{RESULTS}

One hundred twenty-two trained players were grouped into three Somatotypes and classified according to three Age groups (Table 1).

Table 1. Distributions of Endomorphs, Mesomorphs and Ectomorphs in Three Age groups

\begin{tabular}{|l|l|l|l|}
\hline Age Groups & Endomorphs & Mesomorphs & Ectomorphs \\
\hline $\mathbf{1 0 - 1 3}$ yrs & 15 & 9 & 22 \\
\hline $\mathbf{1 4 - 1 6}$ yrs & 8 & 16 & 28 \\
\hline $\mathbf{1 7 - 2 0}$ yrs & 02 & 9 & 13 \\
\hline
\end{tabular}

The highest number of ectomorphs (lean and thin body group) followed by mesomorphs (high-muscle group) and endomorphs (high-fat group) existed among the total players. When classified according to their age, the same players show the highest Ectomorphs in 14-16 years, followed by 10-13 years and 17-20 years Age groups (Table 1).

Table 2. The table shows F values of Age, Height and Weight of trained athletes belonging to different Somatotypes. [p=level of significance, $N S=$ Not significant]

\begin{tabular}{|c|c|c|c|c|c|}
\hline \multirow[t]{2}{*}{ Variables } & \multicolumn{3}{|c|}{ Somatotype Groups } & \multirow{2}{*}{$\begin{array}{c}\text { F } \\
\text { value }\end{array}$} & \multirow{2}{*}{$\begin{array}{c}\text { Level of } \\
\text { significance }\end{array}$} \\
\hline & Endomorph & Mesomorph & Ectomorph & & \\
\hline $\operatorname{Age}(y r)$ & $\begin{array}{c}13.36 \pm 2.45 \\
(n=25)\end{array}$ & $\begin{array}{c}14.44 \pm 1.76 \\
(n=34)\end{array}$ & $\begin{array}{c}14.60 \pm 2.30 \\
(n=63)\end{array}$ & 2.964 & NS \\
\hline Height(cm) & $\begin{array}{c}150.21 \pm 11.47 \\
(n=25)\end{array}$ & $\begin{array}{c}159.88 \pm \\
11.44(n=34)\end{array}$ & $\begin{array}{c}161.7 \pm \\
12.25(\mathrm{n}= \\
63)\end{array}$ & 8.251 & p $<0.05$ \\
\hline Weight(kg) & $\begin{array}{c}47.08 \pm 11.86 \\
(n=25)\end{array}$ & $\begin{array}{c}52.76 \pm 11.69 \\
(n=34)\end{array}$ & $\begin{array}{c}44.31 \pm \\
10.41(n=63)\end{array}$ & 6.275 & $p<0.05$ \\
\hline
\end{tabular}

Statistically, insignificant differences in Age exists among the endomorphs, mesomorphs and ectomorphs (Table 2). The body height was found significantly higher in ectomorphs than endomorphs and mesomorphs, but insignificant differences exist 
Vol 4, No 2 (2021): Stadium -Hungarian Journal of Sport Sciences

between mesomorphs and ectomorphs (Table 3). The weight was significantly higher in mesomorphs than ectomorphs but insignificantly higher (Table 3). The body weight was highest in mesomorphs and lowest in ectomorphs among the three somatotypes.

Table 3. Table showing Scheffe's comparison test of different blood variables of trained athletes belonging to different somatotypes [p=level of significance, NS=Not significant]

\begin{tabular}{|l|c|c|c|}
\hline Variables & $\begin{array}{c}\text { Endomorph } \\
\text { vs } \\
\text { Mesomorph }\end{array}$ & $\begin{array}{c}\text { Mesomorph } \\
\text { vs } \\
\text { Ectomorph }\end{array}$ & $\begin{array}{c}\text { Ectomorph } \\
\text { vs } \\
\text { Endomorph }\end{array}$ \\
\hline Age(yr) & NS & NS & NS \\
\hline Weight(kg) & $9.464, \mathbf{p}<0.05$ & NS & $15.589, \mathbf{p}<0.05$ \\
\hline Weight(kg) & NS & $12.689, \mathbf{p}<0.05$ & NS \\
\hline
\end{tabular}

Table 4. The table shows $F$ values of blood variables of trained athletes belonging to different somatotypes ( $p=$ level of significance, $N S=$ Not Significant).

\begin{tabular}{|c|c|c|c|c|c|}
\hline \multirow{2}{*}{ Variables } & \multicolumn{3}{|c|}{ Somatotype Groups } & $\begin{array}{c}\text { F } \\
\text { value }\end{array}$ & $\begin{array}{c}\text { Level of } \\
\text { significance }\end{array}$ \\
\cline { 2 - 4 } & Endomorph & Mesomorph & Ectomorph & \\
\hline $\begin{array}{c}\text { Creatinine } \\
(\boldsymbol{\mu m o l} / \mathbf{l})\end{array}$ & $\begin{array}{c}82.05 \pm 14.56 \\
(\mathrm{n}=25)\end{array}$ & $\begin{array}{c}88.42 \pm 14.60 \\
(\mathrm{n}=34)\end{array}$ & $\begin{array}{c}81.82 \pm 13.19 \\
(\mathrm{n}=63)\end{array}$ & 2.721 & $\mathrm{NS}$ \\
\hline $\begin{array}{c}\text { Creatine } \\
\text { kinase(U/L) }\end{array}$ & $\begin{array}{c}132.93 \pm 90.0 \\
3\end{array}$ & $\begin{array}{c}184.85 \pm 118 . \\
13\end{array}$ & $\begin{array}{c}212.51 \pm 120 . \\
47 \\
(\mathrm{n}=25)\end{array}$ & $\mathbf{4 . 3 6 1}$ & $\mathbf{p}<\mathbf{0 . 0 5}$ \\
\hline $\begin{array}{c}\text { Creatinine/ } \\
\text { Creatine kinase } \\
\text { Ratio }\end{array}$ & $\begin{array}{c}1.00 \pm 1.30 \\
(\mathrm{n}=25)\end{array}$ & $\begin{array}{c}0.66 \pm 0.41 \\
(\mathrm{n}=34)\end{array}$ & $\begin{array}{c}0.49 \pm 0.25 \\
(\mathrm{n}=63)\end{array}$ & $\mathbf{5 . 6 0 4}$ & $\mathbf{p}<\mathbf{0 . 0 5}$ \\
\hline
\end{tabular}

Statistically insignificant differences exist in creatinine level among the three somatotypes (Table 4). The highest and lowest values were found in mesomorphs and 
endomorphs, respectively, within normal ranges (61.9 - 114.9 micromol/l). The blood's most elevated creatine Kinase levels are found in the ectomorphs, followed by mesomorph and endomorphs (Table 4). Statistically, significant differences were observed between ectomorphs and endomorphs. The ectomorphs and mesomorphs both crossed the typical ranges of creatine kinase level (35 to $175 \mathrm{U} / \mathrm{L}$ ) in the blood (table 4). The creatinine/creatine kinase ratios were statistically significant among the three groups (Table $4 \& 5$ ). The ratio was highest in endomorphs, followed by mesomorphs and ectomorphs.

Table 5. Table showing Scheffe's comparison test of different blood variables of trained athletes belonging to different Somatotypes [p=level of significance, NS=Not significant]

\begin{tabular}{|c|c|c|c|}
\hline Variables & $\begin{array}{l}\text { Endomorph } \\
\text { vs } \\
\text { Mesomorph }\end{array}$ & $\begin{array}{l}\text { Mesomorph } \\
\text { vs } \\
\text { Ectomorph }\end{array}$ & $\begin{array}{c}\text { Ectomorph } \\
\text { vs } \\
\text { Endomorph }\end{array}$ \\
\hline $\begin{array}{c}\text { Creatinine } \\
(\mu \mathrm{mol} / \mathrm{l})\end{array}$ & NS & NS & NS \\
\hline $\begin{array}{c}\text { Creatine } \\
\text { kinase(U/ } \\
\text { L) }\end{array}$ & NS & NS & $18.639, p<0.05$ \\
\hline $\begin{array}{l}\text { Creatinine } \\
\text { /Creatine } \\
\text { Kinase } \\
\text { Ratio(CR/ } \\
\text { CK ratio) } \\
\end{array}$ & $28.9, p<0.05$ & $\begin{array}{l}11.814 \\
p<0.05\end{array}$ & $86.7, p<0.05$ \\
\hline
\end{tabular}

In both cases, creatinine production and phosphocreatine utilisation by creatine kinase enzyme is not the same; production might be higher than the resynthesis. It assumes that in mesomorphs and ectomorphs, phosphocreatine resynthesis and tissue damages might be more significant than endomorphs. The creatinine and creatine kinase levels are higher in mesomorphs and ectomorphs among the three groups. No references and the research report have existed regarding this study to date. This study reveals that further detailed investigations should require for finding out the underlying mechanism.

\section{DISCUSSION}

Somatotyping is the technique by which one can assess a person's body type, regulated by his inherent gene. Inherited three major Somatotypes influenced by physical exercise. Each somatotype can be subdivided into sub-groups because one can't make up muscles or fat but a mixture of both. One can change body type through physical training and proper calorie intake by influencing the physiological and biochemical changes in the body.

In this cross-sectional study, three major body types with specific characteristics are prominent. Each body type can be differentiated, indicating that were calculated the 
Somatotyping technique is satisfactory. The lack of information regarding different important biomarkers about different Somatotypes has become confusing. Still, this cross-sectional study is more curious because cellular metabolism should connect with the body type.

The serum creatinine estimation is essential for understanding the general health status. Each person has their own aerobic/anaerobic metabolism and body type. The muscle mass of persons is related to creatinine production. According to Taylor, men have a greater skeletal muscle mass and have higher creatinine values (Taylor, 1989). Similar findings have been found in this study, as mesomorphs possess the highest amount of creatinine. According to Banfi et al., if the production rate of Creatinine is excessive, there will be a chance of kidney damage (Banfi et al., 2006). According to Gagliano et al., the value of Creatine kinase ranges from 35 to $175 \mathrm{U} / \mathrm{L}$ in the general population and can exceed 16,000 U/L (Gagliano et al., 2099). This considerable variation and inconsistent occurrence are due to different subclinical disorders, genetic influences, physical activities and medication (Prelle et al., 2002). Exhaustive work raises muscle metabolic variables like creatine kinase. In this study, the highest creatine kinase exists in ectomorphs as their event mode is related to continuous endurance activities like long-term running. Interpretation of this marker can be helpful in monitoring recovery from muscular trauma (Banfi et al., 2012). Muscular trauma is more common in ectomorphs than the other two somatotypes. Creatine kinase present in the blood comes primarily from skeletal muscles, and it's reflected in this study when they classify according to their body types.(Ectomorphs $>$ Mesomorphs $>$ Endomorphs). Elevated creatine kinase levels are related to myocardial infarction and various muscle disorders. It is found highest in ectomorphs $(212.51 \pm 120.47 \mathrm{U} / \mathrm{L})$, and lowest in endomorphs $(132.93 \pm 90.03 \mathrm{U} / \mathrm{L})$ and ectomorphs and mesomorphs exceed the normal ranges. Non-modifiable factors like ethnicity, age, gender can also affect enzyme tissue activity and subsequent serum creatine kinase levels. But the most relevant factor, which is directly related to the muscular activity of a person, somatotypes, is somehow overlooked. This study provides two new approaches. Firstly, it tries to find out the changes in external physical traits due to internal cellular metabolism; Secondly, it introduced a new protocol for minimising the confusion of creatine kinase level in blood. The major limitation of this study is due to lacking reference values of creatinine and creatine kinase in this age range and so compared with the standard values. Regarding the justification of evaluating creatine kinase level of blood, standard protocols and more robust guidelines are required for greater scientific integrity because it still is the easiest and reliable indicator of necrotic skeletal tissues. According to Heled et al. (2007), high body fat is associated with higher creatine kinase activity in individuals „I" (101), but in the present study, it is reversed. According to Galarraga et al., different physical and non-physical causes can raise the CK level, and the increased level is associated with varying diseases. However, it is also presented in the healthy individual (Galarraga et al., 2003). This study has found creatine kinase levels in healthy individuals. So, somatotypes should consider when the creatine kinase level interprets because of its direct relation with metabolic activities. This study reveals that the CK level in the blood is more concerned with the lean and thin body type than the fatty type.

The inconsistency of CK level in the blood raised this concept of whether the ratio of creatinine and CK in the blood would be more meaningful as both are metabolically interdependent. For this reason, the proportion of creatinine and creatine kinase is 
estimated in the present study as most of the creatinine synthesis in the muscle is from creatine phosphate with the help of creatine kinase. So, the creatinine present in the blood is the breakdown product of creatine non-enzymatically. Creatinine level in the blood is low when creatine in muscle cells is minor or creatine kinase level of myocytes is poor or absent or inactive. Creatinine level rises during intense exercise for more utilisation of creatine as an energy resource. On the contrary, more phosphocreatine is produced with the help of creatine kinase and resulting in the formation of creatine and ATP. Creatine is the source of creatinine. So, creatinine formation by non-enzymatically, and phosphocreatine $(\mathrm{PCr})$ and creatine $(\mathrm{Cr})$ production by creatine kinase within the myocytes depending upon each other, the more creatine available within the myocytes, more will be creatinine formation. Usually, excess creatinine is eliminated through the urine, and a normal range in the blood is maintained. Dysfunction of kidney and Rhabdomyolysis due to tissue destruction both creatinine and creatine kinase increased in the blood. So, creatinine rises in the blood due to renal dysfunction and excessive physical activities, and creatine kinase increases are still unclear due to different controversial findings. This study provides a ratio of creatinine production and creatine kinase activity in the cellular tissues and the removal of creatinine through the urine and presence of creatine kinase in the serum due to tissue damage. It is a new approach and not considered before. It assumes that when the ratio is 1.0 like other biological systems' ratios, creatinine production and utilisation of creatine kinase are equal and regular. Similarly, when the creatinine excretion and destruction of muscle tissue is equal or constant, would find the ratios 1.0. If the value is $<1$ or $>1$, it may cause an imbalance between creatinine and creatine kinase. In this study, the highest ratios in endomorphs (1.0) and lowest ratios in ectomorphs (0.49) indicated maximum imbalances between creatinine production and minimum utilisation of creatine kinase activity for any reason. In mesomorphs, the same but the higher ratio value than ectomorphs indicated the imbalance of creatinine production and utilisation of the enzyme. We did not compare creatinine and creatine kinase levels separately among the somatotypes. Besides, ectomorphs and mesomorphs have crossed the normal ranges, suggesting some imbalance of creatinine production and creatine kinase utilisation. Less utilisation of creatine kinase in the cytosol leads to reduced creatine phosphate within the myocytes. The creatine and creatine Phosphate ratio in the myocytes might involve leakage of creatine kinase by influencing the AMP-activated protein kinase. However, this study cannot claim that due to its limitations.

So, it assumes that Creatinine and Creatine Kinase Ratio would be more meaningful and appropriate when we relate it with Somatotypes.

\section{CONCLUSION}

This study is mainly concerned with the production of creatinine and creatine phosphate within the myocytes in the presence of creatine kinase and its release in the blood of males having different body types. In this study, a new approach reveals which reflects the production of creatinine and the utilisation of the creatine kinase within the myocytes as both are the primary sources in the blood of humans. Due to considerable variation regarding creatine kinase in the blood, this study highlighted the internal metabolic activities with the external physical traits and tried to find an alternative way to justify the variations by relating with somatotypes. The ratio considers one when the 
balance is maintained correctly. The ratio below one or above one means the imbalance between the two. Endomorphs have proper balance, but the other two somatotypes haven't. The mesomorphs have the highest amount of creatinine due to the high content of myocytes, and that's why creatine kinase is not sufficient to produce proportionate amounts of creatine phosphate hence the chances to release more creatine kinase. The creatinine production is lowest in ectomorphs and the highest creatine kinase level. Thus creatine phosphate production is less, so comparatively less creatinine level in the blood.

\section{Abbreviations}

1. $\mathrm{ADP}=$ Adenosine diphosphate

2. $\mathrm{AMP}=$ Adenosine diphosphate

3. ANOVA = Analysis of Variance

4. ATP = Adenosine triphosphate

5. $\mathrm{CESCORF}=$ Manufacturer of Anthropometric Devices

6. $\mathrm{CK}=$ Creatine Kinase

7. $\mathrm{CK}-\mathrm{BB}=$ Creatine Kinase in Brain

8. $\mathrm{CK}-\mathrm{MB}=$ Creatine Kinase in Blood

9. $\mathrm{CK}-\mathrm{MM}=$ Creatine Kinase in Heart Muscle

10. HWR = Height Weight Ratio

11. IBM SPSS = International Business Mechanics Corporation, Statistical Package for the Social Sciences

12. ISAK = International Society for the Advancement of Kinanthropometry

13. $\mathrm{nm}=$ Nanometre

Acknowledgements: We are sincerely thankful to the Club Authorities, players, and parents. The Department of Physiology, Serampore College conducted this project work and provided every sport and Exercise Physiology Laboratory facility. We are grateful for your immense support.

\section{Declarations}

Funding: Self-funded project.

Conflict of interest: There is no conflict of interest.

Ethics approval (include appropriate approvals or waivers): We have permission before starting this project from the Institutional Human Ethics Committee and followed their instructions.

Consent to participate (include appropriate statements): We have taken permission from Club Authorities and parents of the players after discussing the work plan and benefits of this entire project.

Consent for publication (include appropriate statements): We have no objection to publication if the content is intact and the article's purpose served.

Human and Animal Rights: We have permission before starting this project from the Institutional Human Ethics Committee and followed their instructions. 


\section{REFERENCES}

Banfi G, Del Fabbro M, \& Lippi G (2006). Relation between serum creatinine and body mass index in elite athletes of different sport disciplines Br J Sports Med 40(8):675-8; discussion 678. doi: 10.1136/bjsm.2006.026658. Epub 2006 May 24.PMID: 16723402).

Banfi G, Colombini A, Lombardi G, \& Lubkowska (2012). A Metabolic Markers in Sports Medicine Advances in Clinical Chemistry 56: (2).

Chatterjee P, Bhattacharjee A, Banerjee A, Bandyopadhyay S, \& Bandyopadhyay A (2017). Some important metabolic markers in the blood of trained endomorph, mesomorph and ectomorph male athletes, International Journal of Physiology, Nutrition and Physical Education 2: (1), 335.

Gagliano M, Corona D, \& Giuffrida G et al., (2009). Low-intensity body building exerciseinduced rhabdomyolysis: a case report Cases Journal 2: (1) article 7.

Galarraga B, Sinclair D, Fahie-Wilson MN, McCrae FC, Hull RG, \& Ledingham JM (2003) A rare but important cause for a raised serum creatine kinase concentration: two case reports and a literature review Rheumatology 42: (1) 186-188.

Heath BH, \& Carter JEL (1967). A modified somatotype method. American Journal of Physical Anthropology 27: 57-74.

Huerta-Alardin AL, Varon J, \& Marik PE, (2005) Bench-to-bedside review: rhabdomyolysis—an overview for clinicians Critical Care 9: (2) 158-169.

Khan FY (2009). Rhabdomyolysis: a review of the literature, Netherlands Journal of Medicine 67: (9) 272-283.

Landry DW, \& Bazari H. (2020). Approach to the patient with renal disease. In: Goldman L, Schafer AI, eds. Goldman-Cecil Medicine. 26th ed. Philadelphia, PA: Elsevier chap 106.

Lower Hutt (2011). International Standards for Anthropometric Assessment, ISAK manual, New Zealand.

Marianne F et al. (2012). Creatine-Kinase- and Exercise-Related Muscle Damage Implications for Muscle Performance and Recovery The Review Article.Review Article I Open Access |https://doi.org/10.1155/2012/960363

Perrone RD, \& Madias NE et al., (1992). Serum creatinine as an index of renal function: new insights into old concepts, Clin Chem Oct; 38: (10) 1933-53. 
Ponticos M, Lu QL, Morgan JE, Hardie DG, Partridge TA, \& Carling D, (1998). Dual regulation of the AMP-activated protein kinase provides a novel mechanism for the control of creatine kinase in skeletal muscle EMBO Journal 17:(6) 1688-1699.

Prelle A, Tancredi L, \& Sciacco M et al., (2002) Retrospective study of a large population of patients with asymptomatic or minimally symptomatic raised serum creatine kinase levels Journal of Neurology 249: (3) 305-311.

Sabbagh, M (1988). A kinetic method for the direct determination of creatinine in serum with 3,5-dinitrobenzoic acid without deproteinization, J Clin Chem Clin Biochem.

Taylor E. Howard (1989). Clinical Chemistry. New York: John Wiley and Sons 4: 58-62.

Thompson HS, Scordilis SP, \& De Souza MJ (2006) .Serum creatine kinase activity varies with ovulatory status in regularly exercising, premenopausal women, Hormone Research, 65: (3) 151-158.

Totsuka M, Nakaji S, Suzuki K, Sugawara K, \& Sato K (2002). Break point of serum creatine kinase release after endurance exercise Journal of Applied Physiology 93: (4) 1280-1286.

Online sources

Heled Y, Michael S. Bloom, T. John Wu, Quiona Stephens, \& Patricia A. Deuster (2007). CM-MM and ACE genotypes and physiological prediction of the creatine kinase response to exercise Published Online:01AUG https://doi.org/10.1152/japplphysiol.00081. 